\title{
Variation in Transfusion Practices and the Association with Perioperative Adverse Events in Patients Undergoing Open Abdominal Aortic Aneurysm Repair and Lower Extremity Arterial Bypass in the Vascular Quality Initiative
}

\author{
Zachary Osborne ${ }^{1}$, Kristine Hanson ${ }^{1}$, Benjamin S. Brooke ${ }^{2}$, Marc Schermerhorn ${ }^{3}$, Peter \\ Henke $^{4}$, Rumi Faizer ${ }^{5}$, Andres Schanzer ${ }^{6}$, Philip Goodney ${ }^{7}$, Thomas Bower ${ }^{1}$, Randall R. \\ DeMartino ${ }^{1}$, and for the Vascular Quality Initiative \\ ${ }^{1}$ Division of Vascular and Endovascular Surgery, Mayo Clinic, Rochester, MN \\ ${ }^{2}$ Section of Vascular Surgery, The University of Utah School of Medicine, Salt Lake City, UT \\ ${ }^{3}$ Division of Vascular and Endovascular Surgery, Beth Israel Deaconess Medical Center, Boston, \\ MA \\ ${ }^{4}$ Section of Vascular Surgery, University of Michigan, Ann Arbor, MI \\ ${ }^{5}$ Division of Vascular Surgery, University of Minnesota, Minneapolis, MN \\ ${ }^{6}$ Division of Vascular Surgery, University of Massachusetts Medical Center, Worcester, MA \\ ${ }^{7}$ Section of Vascular Surgery, Dartmouth-Hitchcock Medical Center, Hanover, $\mathrm{NH}$
}

\begin{abstract}
Background-Blood transfusions are associated with adverse events. We examined perioperative transfusion practices and associated complications following open vascular procedures nationwide in the Vascular Quality Initiative (VQI).

Methods-Adults undergoing open abdominal aortic aneurysm repair (OAR) and lower extremity arterial bypass (Bypass) within VQI (2003-2016) were identified. All emergent cases, patients with preoperative hemoglobin $<7 \mathrm{~g} / \mathrm{dL}$, preoperative hospitalization $>1$ day, or a return to operating room during the index hospitalization were excluded. Units of red blood cells transfused were the primary outcome. Secondary outcomes were postoperative myocardial infarction (MI) and death. Patient, center, and procedural factors were evaluated. Multivariable mixed effects negative binomial regression and multivariable logistic regression were performed.
\end{abstract}

Results-We identified 24,131 procedures (OAR 3885, 16.1\%; Bypass 20,246, 83.9\%) among 22,532 patients (10.1\% had $>1$ procedure). Overall, $37.5 \%$ of OAR and $19.5 \%$ of Bypass were transfused. Transfusion rates varied across estimated blood loss quartiles and across various

Correspondence to: Randall R. DeMartino, Department of Vascular and Endovascular Surgery, Mayo Clinic, 200 First Street SW, Rochester, MN 55905, USA; demartino.randall@mayo.edu.

Presented at VESS 2017 Winter meeting.

SUPPLEMENTARY DATA

Supplementary data related to this article can be found at http://dx.doi.org/10.1016/j.avsg.2017.06.154 
preoperative hemoglobin levels. The overall rate of postoperative MI and death was $4.0 \%$ and $1.8 \%$ for OAR, and $2.2 \%$ and $0.7 \%$ for Bypass, respectively. In univariate and multivariable analysis, transfusions were associated with an increased risk of postoperative MI and death. A mixed effects negative binomial model demonstrated variation in transfusions across centers $(\mathrm{P}<$ $0.001)$. Female gender and preoperative anemia were significantly associated with transfusions.

Conclusions-Blood transfusions are variable across centers in VQI. Transfusions are associated with a higher postoperative MI and death after OAR and Bypass. Efforts to reduce transfusion may focus on center variability, gender, and preoperative anemia.

\section{INTRODUCTION}

Anemia is a common finding in vascular surgery patients before and after surgery. It is a risk factor for acute coronary syndromes and a strong predictor of major adverse cardiovascular events. ${ }^{1-5}$ In patients undergoing noncardiac ${ }^{6-9}$ and cardiac procedures, ${ }^{10-12}$ perioperative anemia has been associated with worse clinical outcomes and increased incidence of perioperative myocardial infarction (MI). In patients undergoing infrainguinal bypass, anemia (hematocrit $<28 \%$ ) has been associated with an increased rate of perioperative cardiac events. ${ }^{13}$

Transfusion of red blood cells offers an immediate correction for anemia, increasing tissue oxygen delivery. However, transfusions have been associated with adverse events, including an increase in perioperative MIs. ${ }^{14-16}$ Based on multiple randomized clinical trials and systematic reviews, national organizations advocate a restrictive transfusion strategy using a trigger hemoglobin level of $\leq 7$ or below for noncardiac surgeries and recommend avoiding transfusing to hemoglobin levels above $10 \mathrm{mg} / \mathrm{dL}$. Despite these data recommending a restrictive transfusion strategy, ${ }^{17-25}$ some reports have suggested that certain subgroups of patients, like cardiac surgery patients, may experience fewer cardiac complications if a more liberal trigger level of $9 \mathrm{~g} / \mathrm{dL}$ is used. ${ }^{11}$ However, there is a paucity of data that has evaluated the association of blood transfusions on perioperative outcomes following vascular surgery, and the limited studies have provided mixed results. ${ }^{13,26-28}$

Given the conflicting data on transfusion practices in vascular surgery patients, we sought to utilize the Vascular Quality Initiative (VQI) dataset to investigate transfusion practices and predictors for blood transfusions among patients undergoing elective open abdominal aortic aneurysm repair (OAR) and arterial bypass (Bypass). The VQI is a national quality improvement registry that allows a comprehensive assessment of perioperative risk factors for transfusions within a broad sample of academic and community hospitals. Additionally, we sought to understand the associated risk of perioperative mortality and MI with red blood cell transfusions in this patient group.

\section{METHODS}

\section{Patient Selection}

Utilizing the VQI database, we identified all patients aged 18 and older who underwent an elective OAR, suprainguinal bypass, or infrainguinal bypass at participating hospitals from January 2003 to April 2016. Bypasses are reported as either infrainguinal bypass (with the 
most proximal inflow from the common femoral artery [CFA] or distal sources of inflow) or suprainguinal bypass (with an inflow more proximal than the CFA, such as the aorta, axillary, common iliac, or the external iliac artery). Both infrainguinal bypass and suprainguinal bypass were combined for analysis as the Bypass group. We excluded all urgent and emergent cases ( $n=11,229 ; 2269$ OAR, 8960 bypass) including rupture open AAA repairs, and cases with a return to the operating room for any reason. We also excluded patients with preoperative hemoglobin $7 \mathrm{~g} / \mathrm{dL}$ (these patients had an immediate indication to proceed with transfusion prior to surgery) and patients who were hospitalized $>1$ day prior to their operation (these patients may have been transfused prior to their surgery). VQI tracks total in-hospital transfusions so it is impossible to differentiate patients who underwent blood transfusion prior to surgery from those who underwent blood transfusion during or after surgery. We excluded Bypass cases without general anesthesia, as well as OAR and suprainguinal bypass cases that underwent a concomitant infrainguinal bypass. Finally, we excluded patients with unknown data on transfusion or any inclusion/exclusion criteria. The goal of this approach is to be able to describe the current practice of transfusions for elective and uncomplicated patients undergoing vascular procedures across institutions. Due to the deidentified nature of the VQI, this study was exempt from review by the Mayo Clinic Institutional Review Board and the need for consent was waved.

\section{Outcomes}

The primary outcome of the study was the use of packed red blood cell (pRBC) transfusion practices among participating VQI hospitals. This was calculated based on the number of transfused units of pRBCs given during the hospitalization for patients undergoing elective OAR and Bypass. VQI records the total number of pRBC transfused from admission to discharge. Transfusions were analyzed by the center. We analyzed transfusions across VQI by operation (OAR or Bypass), preoperative hemoglobin levels ( $\geq 7$ to $<10,10-12,>12 \mathrm{~g}$ / $\mathrm{dL}$ ), and estimated blood loss (EBL) quartiles ( $<100,100-250,>250-600$, and $\succ 600 \mathrm{~mL})$ to adjust for various levels of initial hemoglobin, acute blood loss anemia, and magnitude of operation. Our secondary outcomes included postoperative in-hospital mortality and postoperative MI. Postoperative MI is defined as either an electrocardiogram or clinical MI consistent with MI, or an isolated troponin elevation without electrocardiogram ischemic changes or clinical symptoms.

\section{Statistical Analysis}

Our primary outcome of pRBC transfusion was compared across patient demographics and operative factors. In addition, we assessed the association of number of transfused pRBC with our secondary outcomes of mortality and MI. Associations with the outcomes of any transfusion, mortality, and MI were assessed initially using chi-squared tests for categorical variables, Fisher's exact tests for low frequency events, and Student's $t$-tests for continuous variables. For the outcome of pRBC transfusion, multivariable mixed effects negative binomial regression models were used to evaluate the factors associated with the number of pRBC units transfused, where center was included as a random effect. Negative binomial regression was chosen because $\mathrm{pRBC}$ transfusion is a nonparametric event where most patients receive $0-2 \mathrm{U}$ of pRBCs with a severely right-skewed distribution. For the outcomes of mortality and MI, we used fixed effects multivariable logistic regression models. 
Variables of clinical significance and those with a value of $P<0.1$ by univariate analysis were included in multivariable regressions.

In our multivariable analyses, we adjusted for other potentially confounding operative factors including EBL, procedure time, proximal clamp position (OAR patients only), and inflow origin (aortic versus nonaortic for Bypass patients only). We also adjusted for centerlevel procedural volume. To adjust for patient-related factors, we included age, gender, presence of coronary artery disease $(\mathrm{CAD})$ with or without revascularization, prior coronary artery bypass grafting or percutaneous coronary intervention (CABG/PCI), chronic obstructive pulmonary disease (COPD), smoking, congestive heart failure (CHF), chronic kidney disease, ambulatory status, region, preoperative stress test, diabetes mellitus (DM), year of surgery, and preoperative medication use as covariates. Patients with multiple separate operations were evaluated independently. $P$ values of $<0.05$ were considered significant. Analyses were performed using SAS version 9.4 (Cary, NC) and R version 3.1.1.

\section{RESULTS}

We identified 24,131 procedures in VQI from 22,532 patients who met our inclusion criteria. This comprised 3,885 (16.1\%) OAR and 20,246 (83.9\%) Bypass operations. Of the Bypass operations, most $(15,020,74.2 \%)$ were infrainguinal bypasses. The remaining were suprainguinal bypasses $(5,226,25.8 \%)$. Of all patients, $10.1 \%$ underwent more than 1 procedure during the study interval. Overall, $67.7 \%$ of patients were male, $27.8 \%$ had a documented history of CAD, 27.9\% had a documented history of COPD, $85.4 \%$ had documented hypertension, and $35.3 \%$ had DM. Patient characteristics are listed in Table I.

During the study period, there were 214 centers that reported procedure data to the VQI. Centers reporting to the VQI averaged $30.4 \pm 26.3$ elective OAR and Bypass procedures annually (range 1-147). The average annual number of elective OAR cases across centers was $5.0 \pm 7.7$ (range 0-74) and the annual mean number of Bypass per center was 25.4 \pm 23.4 (range $0-138$ ).

\section{Factors Associated with Transfusions}

Overall, 1,457 (37.5\%) of OAR and 3,941 (19.5\%) of bypasses received a transfusion. Of the Bypass cases, 1,354 (25.9\%) suprainguinal and 2,587 (17.2\%) infrainguinal bypass cases received a transfusion. OAR cases had a higher number of pRBCs $(1.1 \pm 2.2 \mathrm{U})$ transfused compared with $0.5 \pm 1.30 \mathrm{U}$ for bypass cases $(P<0.001)$. There was variability in the use of transfusions both across EBL and preoperative anemia strata for each procedure (Table II). For example, for patients undergoing Bypass with preoperative hemoglobin $<10$ and lowest EBL quartile, there was a range of $0-8 \mathrm{U}$ of pRBC transfused. For patients with hemoglobin levels $>12$ and an EBL of $>600 \mathrm{~mL}, 0-44 \mathrm{U}$ of pRBCs were transfused. Similar variability in transfusion across preoperative hemoglobin levels and EBL was seen in OAR procedures (Table II). Although all OARs included in this analysis were infrarenal repairs, placing the clamp more proximal on the aorta was associated with increasedlikelihood of transfusion (31\% forinfrarenal cross-clamp position, $43 \%$ above one or both renal arteries, and $57 \%$ for supraceliac clamp, $P<0.001)$. 
Univariate analysis demonstrated that female gender, increasing age, having a history of CAD, hypertension, history of CABG/PCI, CHF, and a preoperative hemoglobin $<10 \mathrm{~g} / \mathrm{dL}$ were all statistically significantly associated with increased rates of transfusion for both OAR and Bypass (Appendix A). Insulin-dependent diabetes was associated with increased transfusions for OAR, while any DM was associated with transfusion for Bypass. Any COPD was associated with increased transfusions for Bypass, while only medically treated COPD was associated with transfusion for OAR.

Multivariable models demonstrated female gender, increasing age, hypertension (OAR only), prior CABG/PCI, longer procedure times, preoperative anemia, and EBL $>600 \mathrm{~mL}$ compared with $\_50$ was all associated with increased transfusions (Table III). Antiplatelet use was not associated with transfusion for OAR cases, but was associated with increased risk of transfusion for Bypass cases. More proximal clamp position was associated with higher rate of transfusion for OAR. Aortic (versus nonaortic) graft origin was not associated with increased transfusion for Bypass cases.

\section{Factors Associated with Myocardial Infarction and Postoperative Death}

Postoperative MI occurred in 157 (4.0\%) OAR repairs and in 451 (2.2\%) Bypasses. Of the Bypasses, 145 (2.8\%) suprainguinal bypasses and 306 (2.0\%) infrainguinal bypasses developed an MI. Upon univariate analysis, any transfusion was associated with an increased risk of postoperative MI (2.6\% with no transfusion versus $6.5 \%$ with any transfusion, $P<$ 0.001 ) for OAR and Bypass (1.0\% with no transfusion versus $7.4 \%$ with any transfusion, $P<$ 0.001). Additionally, increasing age, female gender (Bypass only), cardiac disease, prior $\mathrm{CABG} / \mathrm{PCI}, \mathrm{CHF}$, abnormal stress test, ambulatory status, and procedure time were associated with increased risk of MI for both OAR and Bypass (Appendix B). After adjustment for age, surgery year, and other demographics, a multivariable logistic regression analysis demonstrated that transfusions were associated with increased odds of MI (odds ratio [OR] 1.2/unit, 95\% confidence interval [CI] 1.1-1.2, $P<0.001$ for OAR; OR 1.3, 95\% CI 1.2-1.4, $P<0.001$ for Bypass; Table IV).

In-hospital postoperative death occurred in 70 (1.8\%) OAR and in $133(0.7 \%)$ Bypass. In the bypass group, $51(1.0 \%)$ suprainguinal bypass and $82(0.5 \%)$ infrainguinal bypass patients died. Upon univariate analysis, transfusions were associated with an increased risk of death for both OAR $(0.7 \%$ with no transfusion versus $3.7 \%$ with any transfusion, $P<0.001)$ and Bypass $(0.3 \%$ with no transfusion versus $2.1 \%$ with any transfusion $<0.001)$. Additionally, increasing age, $\mathrm{CAD}, \mathrm{CHF}$, nonambulatory status, increasing procedure time, preoperative anemia, and increasing EBL were associated with postoperative mortality for both OAR and Bypass (Appendix C). After adjustment for age, gender, surgery year, and other demographics, multivariable logistic regression models demonstrated that transfusions were associated with increased mortality (OR 1.3/unit, 95\% CI 1.2-1.4, $P<0.001$ for OAR; OR $1.3,95 \%$ CI 1.3-1.4 for Bypass, $P<0.001$ ). For Bypass cases, age, history of CAD, CHF, EBL > $600 \mathrm{~mL}$ compared with $\_50 \mathrm{~mL}$, and procedure times $3.5-5 \mathrm{hr}$ and over $5 \mathrm{hr}$ compared with $<2.5 \mathrm{hr}$ were also associated with higher odds of mortality (Table V) while a history of prior $\mathrm{CABG} / \mathrm{PCI}$ was protective. 


\section{DISCUSSION}

Although the transfusion of red blood cells offers an immediate therapy for anemia, they are not a benign therapy. Transfusions have been associated with many adverse events, including an increase in perioperative MIs. ${ }^{14-16}$ In this study, we describe variability in the use of perioperative transfusions for elective OAR and Bypass cases in the VQI when controlling for anemia and EBL. Women, older patients, preoperative anemia, and those with CAD are associated with a higher likelihood of receiving transfusions, in addition to case complexity surrogates such as operative time and EBL. The use of transfusions is significantly associated with the risk of MI and death postoperatively. Although many of these factors are difficult to control, knowledge of their associated risk may help providers to identify highrisk patient groups for transfusions and be able to target transfusion reduction strategies.

In the context of transfusions, there are little data focused specifically on vascular surgery patients and how transfusions impact perioperative outcomes. The few available studies demonstrate mixed results. ${ }^{13,26-28}$ Bush et al. randomized patients preoperatively who were undergoing elective aortic and infrainguinal surgery to receive either liberal $(<10 \mathrm{~g} / \mathrm{dL})$ or restrictive strategy $(<7 \mathrm{~g} / \mathrm{dL})$ of transfusion. They demonstrated no difference in the rate of myocardial ischemia or death between transfusion strategy groups. However, in a retrospective observational study, Bursi et al. reviewed patients admitted for major elective vascular surgery and demonstrated that patients who received transfusions had significantly worse outcomes: with a higher risk of 30-day death (hazard ratio [HR] 11.72, 95\% CI 3.92$35.10, P<0.0001)$, MI (HR 3.32, 95\% CI 1.75-6.27, $P=0.0003$ ), and the composite end point of MI or death (HR 4.02, 95\% CI 2.23-7.27, $P=0.0001$ ).

In a similar study by Obi et al., researchers demonstrated that transfusions were associated with an increased rate of MI/death. They reviewed a multicenter statewide quality improvement registry of a 22-hospital consortium in Michigan from 2012 to 2013. They reviewed patients undergoing peripheral artery bypass, endovascular aortic repairs, and open aortic aneurysm repair. In their cohort, $24.8 \%$ of patients received a perioperative transfusion. Similar to our results, those with preoperative anemia, CAD, DM, CHF, previous $\mathrm{CABG}$, cerebrovascular disease, and those on hemodialysis were more likely to receive a transfusion. Our results also demonstrate similar findings in VQI for patients with $\mathrm{CAD}$, COPD, diabetes, preoperative anemia, and history of myocardial disease. We also demonstrated that those who undergo elective OAR and Bypass procedures requiring transfusion have similarly higher rates of MI or postoperative death. Interestingly, we demonstrated that women were more likely to be transfused and our data additionally demonstrate that women who received a transfusion had an associated higher rate of MI and mortality. Two important differences exist between our studies. First, they reviewed a statewide registry while we reviewed a national registry. Second, they did include urgent repairs in their analysis while we did not. In both studies, emergent cases were excluded. ${ }^{29}$

In an effort to reduce transfusions, identification of high risk patients is necessary. In our analysis, several factors are closely associated with the need for transfusions. Many risk factors may not be modifiable, such as age and sex. Additionally, operative time and EBL may not be easily modifiable factors. Yet, this emphasizes that technique and efficiency in 
the operating room are associated with significant impact on patient outcomes. Potentially, the most modifiable risk factor is preoperative anemia. We identified that preoperative hemoglobin levels $<12 \mathrm{mg} / \mathrm{dL}$ were significantly associated with transfusions. Efforts to resolve underlying anemia may reduce the need for transfusion perioperatively.

Although a transfusion trigger threshold is critical for the postoperative period, preoperative optimization and prevention of the need for a transfusion is equally elusive. Unfortunately, preoperative iron supplementation has had mixed results with regards to decreasing the need for a postoperative transfusion. There are 3 prospective randomized controlled trials concerning preoperative iron supplementation. In review of the gynecology literature, there are some indications that preoperative intravenous iron supplementation does decrease perioperative transfusions in patients with preoperative menorrhagia. However, in the colorectal literature the benefit of preoperative supplementation is mixed. Dr. Lidder did show a decrease in postoperative transfusions when preoperative anemic patients were given oral ferrous sulfate. However, Edwards et al. found no difference in postoperative transfusion requirements when preoperative intravenous iron supplementation was given. Preoperative evaluation by a dedicated center may help with decreasing variation in perioperative cardiac medications and risk factor modification. ${ }^{30-32}$

Based on multiple randomized controlled clinical trials, guidelines recommend that for nonbleeding patients, a hemoglobin level of 7 or below should trigger transfusion for noncardiac surgeries, and one should avoid transfusing above a level of $10 \mathrm{mg} / \mathrm{dL} .{ }^{17-25}$ Others have found that a restrictive strategy is unfavorable and that transfusions of cardiac surgery patients to a level of $9 \mathrm{~g} / \mathrm{dL}$ yield fewer cardiac events. ${ }^{11}$ Despite these recommendations, controversy remains about the use and extent of transfusions for patients who are stable or without symptoms, for more complex patients with multiple comorbidities, and for vascular surgery patients who develop anemia due to acute blood loss. In our analysis, it appears that CAD was associated with a higher risk of transfusions. This may indicate that those with $\mathrm{CAD}$ are transfused at more liberal triggers to potentially reduce the risk of cardiac ischemia. In addition, there was variability in the use of transfusion across centers. Optimal thresholds for transfusion in the vascular surgery population are illdefined and likely lead to this variation. Further work is needed to define these thresholds so optimization strategies for transfusions can be successful. Fortunately, there is a multicenter randomized controlled trial that is underway that will address this question in a more definitive way. Dr. Kouglas and fellow researchers at Baylor College of Medicine are currently conducting the "TOP Trial: Transfusion Triggers after Operations in High Cardiac Risk Patients." They will assign patients to a liberal (hemoglobin $<10 \mathrm{gm} / \mathrm{dL}$ ) or a restrictive group (hemoglobin $<7 \mathrm{gm} / \mathrm{dL}$ ) transfusion trigger threshold and look at the 90 mortality and other ischemic events in this high-risk population.

Our study has several limitations. Although we expect most blood loss requiring transfusion to occur in the operating room, VQI does not gather other causes for bleeding during the perioperative period, such as gastrointestinal bleeding. Thus, some patients will need transfusions out of perioperative window for other causes that we were unable to account for. To minimize this confounding, we have limited our study to only elective procedures and we excluded returns to the operating room to limit other reasons for transfusion. 
Additionally, we were only able to determine the total number of transfusions during an admission in VQI. We assumed that most transfusions were administered in the perioperative period from operative blood loss and other episodes occur at random within surgical types. Furthermore, the specific indication for transfusion (hypovolemia, cardiac ischemia, symptomatic anemia, need for pressors, tachycardia, or acidosis) and the nadir hemoglobin is not tracked in VQI. Likewise, no temporal data are available as to when the transfusion was given during the hospitalizations (i.e., intraoperative, immediately postoperatively, or multiple days later). We have stratified patients according to the EBL and preoperative hemoglobin to minimize the confounding of nadir hemoglobin. Finally, the timing from transfusion to MI is unknown. Further efforts to describe the context of transfusion and MI after vascular surgery are necessary. Perhaps the most significant limitation of this study and all the published literature to date on this topic is that we are no closer to determining the optimum transfusion threshold for patients undergoing major vascular surgery. This remains a significant unmet need that warrants further investigations with prospective study.

\section{CONCLUSION}

Our data suggest there is significant variation with regards to transfusion of pRBCs following major vascular surgery procedures in hospitals within VQI. We have identified specific patient groups that are at high risk for transfusion after OAR and bypass.

Additionally, the use of transfusions is significantly associated with postoperative MI and death after OAR and Bypass. These data are important to understand drivers of transfusions during and after vascular surgery. This work can help to inform practice efforts to reduce transfusion use. Ideally, future randomized controlled trials can be performed to better understand the impact of using different transfusion strategies after vascular surgery on postoperative outcomes. Immediate efforts to reduce transfusion may focus on center variability, sex, and preoperative anemia.

\section{Supplementary Material}

Refer to Web version on PubMed Central for supplementary material.

\section{Acknowledgments}

The authors would like to acknowledge the Robert D. and Patricia E. Kern Center for the Science of Health Care Delivery at Mayo Clinic for their assistance with statistical analysis of data for this manuscript.

\section{References}

1. Sabatine MS, Morrow DA, Giugliano RP, et al. Association of hemoglobin levels with clinical outcomes in acute coronary syndromes. Circulation. 2005; 111:2042-9. [PubMed: 15824203]

2. Eagle KA, Coley CM, Newell JB, et al. Combining clinical and thallium data optimizes preoperative assessment of cardiac risk before major vascular surgery. Ann Intern Med. 1989; 110:859-66. [PubMed: 2655519]

3. Fleisher LA, Rosenbaum SH, Nelson AH, et al. The predictive value of preoperative silent ischemia for postoperative ischemic cardiac events in vascular and nonvascular surgery patients. Am Heart J. 1991; 122:980-6. [PubMed: 1927885] 
4. Norgren L, Hiatt WR, Dormandy JA, et al. Inter-society consensus for the management of peripheral arterial disease (TASC II). J Vasc Surg. 2007; 45:S5-67. [PubMed: 17223489]

5. Raby KE, Goldman L, Creager MA, et al. Correlation between preoperative ischemia and major cardiac events after peripheral vascular surgery. N Engl J Med. 1989; 321:1296-300. [PubMed: 2797102]

6. Baron DM, Hochrieser H, Posch M, et al. Preoperative anaemia is associated with poor clinical outcome in noncardiac surgery patients. Br J Anaesth. 2014; 113:416-23. [PubMed: 24829444]

7. Carson JL, Duff A, Poses RM, et al. Effect of anaemia and cardiovascular disease on surgical mortality and morbidity. Lancet. 1996; 348:1055-60. [PubMed: 8874456]

8. Carson JL, Noveck H, Berlin JA, et al. Mortality and morbidity in patients with very low postoperative $\mathrm{Hb}$ levels who decline blood transfusion. Transfusion. 2002; 42:812-8. [PubMed: 12375651]

9. Musallam KM, Tamim HM, Richards T, et al. Preoperative anaemia and postoperative outcomes in non-cardiac surgery: a retrospective cohort study. Lancet. 2011; 378:1396-407. [PubMed: 21982521]

10. Carrascal Y, Maroto L, Rey J, et al. Impact of preoperative anemia on cardiac surgery in octogenarians. Interact Cardiovasc Thorac Surg. 2010; 10:249-55. [PubMed: 19889715]

11. Murphy GJ, Pike K, Rogers CA, et al. Liberal or restrictive transfusion after cardiac surgery. N Engl J Med. 2015; 372:997-1008. [PubMed: 25760354]

12. Ranucci M, Baryshnikova E, Castelvecchio S, et al. Major bleeding, transfusions, and anemia: the deadly triad of cardiac surgery. Ann Thorac Surg. 2013; 96:478-85. [PubMed: 23673069]

13. Nelson AH, Fleisher LA, Rosenbaum SH. Relationship between postoperative anemia and cardiac morbidity in high-risk vascular patients in the intensive care unit. Crit Care Med. 1993; 21:860-6. [PubMed: 8504653]

14. Hollis RH, Singletary BA, McMurtrie JT, et al. Blood transfusion and 30-day mortality in patients with coronary artery disease and anemia following noncardiac surgery. JAMA Surg. 2016; 151:139-45. [PubMed: 26444569]

15. Smilowitz NR, Oberweis BS, Nukala S, et al. Association between anemia, bleeding, and transfusion with long-term mortality following noncardiac surgery. Am J Med. 2016; 129:315323.e2. [PubMed: 26524702]

16. Whitlock EL, Kim H, Auerbach AD. Harms associated with single unit perioperative transfusion: retrospective population based analysis. BMJ. 2015; 350:h3037. [PubMed: 26070979]

17. Ad N, Massimiano PS, Burton NA, et al. Effect of patient age on blood product transfusion after cardiac surgery. J Thorac Cardiovasc Surg. 2015; 150:209-14. [PubMed: 25896463]

18. Carson JL, Brooks MM, Abbott JD, et al. Liberal versus restrictive transfusion thresholds for patients with symptomatic coronary artery disease. Am Heart J. 2013; 165:964-971.e1. [PubMed: 23708168]

19. Carson JL, Sieber F, Cook DR, et al. Liberal versus restrictive blood transfusion strategy: 3-year survival and cause of death results from the FOCUS randomised controlled trial. Lancet. 2015; 385:1183-9. [PubMed: 25499165]

20. Carson JL, Terrin ML, Noveck H, et al. Liberal or restrictive transfusion in high-risk patients after hip surgery. N Engl J Med. 2011; 365:2453-62. [PubMed: 22168590]

21. Hajjar LA, Vincent JL, Galas FR, et al. Transfusion requirements after cardiac surgery: the TRACS randomized controlled trial. JAMA. 2010; 304:1559-67. [PubMed: 20940381]

22. Hebert PC, Wells G, Blajchman MA, et al. A multicenter, randomized, controlled clinical trial of transfusion requirements in critical care. Transfusion Requirements in Critical Care Investigators, Canadian Critical Care Trials Group. N Engl J Med. 1999; 340:409-17. [PubMed: 9971864]

23. Hebert PC, Wells G, Tweeddale M, et al. Does transfusion practice affect mortality in critically ill patients? Transfusion Requirements in Critical Care (TRICC) Investigators and the Canadian Critical Care Trials Group. Am J Respir Crit Care Med. 1997; 155:1618-23. [PubMed: 9154866]

24. Hebert PC, Yetisir E, Martin C, et al. Is a low transfusion threshold safe in critically ill patients with cardiovascular diseases? Crit Care Med. 2001; 29:227-34. [PubMed: 11246298]

25. Holst LB, Haase N, Wetterslev J, et al. Lower versus higher hemoglobin threshold for transfusion in septic shock. N Engl J Med. 2014; 371:1381-91. [PubMed: 25270275] 
26. Bursi F, Barbieri A, Politi L, et al. Perioperative red blood cell transfusion and outcome in stable patients after elective major vascular surgery. Eur J Vasc Endovasc Surg. 2009; 37:311-8. [PubMed: 19111480]

27. Bush RL, Pevec WC, Holcroft JW. A prospective, randomized trial limiting perioperative red blood cell transfusions in vascular patients. Am J Surg. 1997; 174:143-8. [PubMed: 9293831]

28. Kougias P, Orcutt S, Pak T, et al. Impact of postoperative nadir hemoglobin and blood transfusion on outcomes after operations for atherosclerotic vascular disease. J Vasc Surg. 2013; 57:1331-7. [PubMed: 23384496]

29. Obi AT, Park YJ, Bove P, et al. The association of perioperative transfusion with 30-day morbidity and mortality in patients undergoing major vascular surgery. J Vasc Surg. 2015; 61:1000-1009.e1. [PubMed: 25596978]

30. Edwards TJ, Noble EJ, Durran A, et al. Randomized clinical trial of preoperative intravenous iron sucrose to reduce blood transfusion in anaemic patients after colorectal cancer surgery. Br J Surg. 2009; 96:1122-8. [PubMed: 19731228]

31. Kim YH, Chung HH, Kang SB, et al. Safety and usefulness of intravenous iron sucrose in the management of preoperative anemia in patients with menorrhagia: a phase IV, open-label, prospective, randomized study. Acta Haematol. 2009; 121:37-41. [PubMed: 19332985]

32. Lidder PG, Sanders G, Whitehead E, et al. Pre-operative oral iron supplementation reduces blood transfusion in colorectal surgeryda prospective, randomised, controlled trial. Ann R Coll Surg Engl. 2007; 89:418-21. [PubMed: 17535624] 


\section{Table I}

Patient characteristics for $\mathrm{OAR}$ and $\mathrm{AB}$ procedures

\begin{tabular}{|c|c|c|c|c|}
\hline \multirow[b]{2}{*}{ Risk factor } & \multicolumn{3}{|l|}{ Procedure type } & \multirow[b]{2}{*}{$P$ value } \\
\hline & All $(n=24,131)$ & OAR $(n=3,885)$ & Bypass $(n=20,246)$ & \\
\hline \multicolumn{5}{|l|}{ Gender } \\
\hline Male, $\%$ & 67.7 & 73.3 & 66.6 & $<0.001$ \\
\hline \multicolumn{5}{|l|}{ Age } \\
\hline Mean (standard deviation) & $66.2(10.5)$ & $69.2(8.3)$ & $65.7(10.7)$ & $<0.001$ \\
\hline \multicolumn{5}{|l|}{ CAD } \\
\hline$\%$ & 27.8 & 25.6 & 28.2 & $<0.001$ \\
\hline \multicolumn{5}{|l|}{ COPD } \\
\hline$\%$ & 27.9 & 31.8 & 27.1 & $<0.001$ \\
\hline \multicolumn{5}{|l|}{ Smoking status } \\
\hline Ever smoked (prior or current), $\%$ & 89.0 & 90.9 & 88.6 & $<0.001$ \\
\hline \multicolumn{5}{|l|}{ Hypertension } \\
\hline$\%$ & 85.4 & 84.1 & 85.6 & 0.02 \\
\hline \multicolumn{5}{|l|}{ Diabetes } \\
\hline Diet, $\%$ & 4.0 & 3.9 & 4.0 & $<0.001$ \\
\hline Noninsulin meds, \% & 15.9 & 9.7 & 17.1 & \\
\hline Insulin, $\%$ & 15.5 & 2.7 & 17.9 & \\
\hline \multicolumn{5}{|l|}{$\mathrm{CHF}$} \\
\hline$\%$ & 11.1 & 6.8 & 11.9 & $<0.001$ \\
\hline \multicolumn{5}{|l|}{ Total procedure time category } \\
\hline Not available, $n$ & 1,955 & 17 & 1,938 & \\
\hline$<2.5 \mathrm{hr}, \%$ & 21.2 & 12.5 & 23.0 & $<0.001$ \\
\hline 2.5 to $<3.5 \mathrm{hr}, \%$ & 28.0 & 29.6 & 27.7 & \\
\hline 3.5 to $<5 \mathrm{hr}, \%$ & 29.9 & 34.4 & 28.9 & \\
\hline$>5 \mathrm{hr}, \%$ & 21.0 & 23.5 & 20.4 & \\
\hline \multicolumn{5}{|l|}{ Proximal clamp position (OAR) } \\
\hline Infrarenal, $\%$ & & 55.3 & - & \\
\hline Above one renal, $\%$ & & 14.8 & - & \\
\hline Above both renals, $\%$ & & 23.5 & - & \\
\hline Supraceliac, $\%$ & & 6.4 & - & \\
\hline \multicolumn{5}{|l|}{ Preoperative hemoglobin } \\
\hline Not available, $n$ & 1,069 & 87 & 982 & \\
\hline$<10, \%$ & 6.1 & 2.9 & 6.7 & $<0.001$ \\
\hline 10 to $<12$ & 18.8 & 12.9 & 20.0 & \\
\hline $12+$ & 75.1 & 84.2 & 73.3 & \\
\hline
\end{tabular}

$\mathrm{AB}$, arterial bypass. 


\section{Table II}

Transfusions across EBL quartiles for OAR and AB stratified by preoperative hemoglobin levels

\begin{tabular}{|c|c|c|c|c|}
\hline \multirow[b]{2}{*}{ Preoperative hemoglobin } & \multicolumn{4}{|l|}{ EBL quartile } \\
\hline & $<100 \mathrm{~mL}$ & $100-250 \mathrm{~mL}$ & $>250-600 \mathrm{~mL}$ & $>600 \mathrm{~mL}$ \\
\hline \multicolumn{5}{|l|}{ OAR } \\
\hline \multicolumn{5}{|l|}{$<10$} \\
\hline$N$ transfused $/ N$ total, $\%$ transfused & $1 / 2(50.0 \%)$ & $2 / 4(50.0 \%)$ & $6 / 13(46.2 \%)$ & $66 / 92(71.7 \%)$ \\
\hline Median (IQR) & $5(0-10)$ & $1.5(0-3)$ & $0(0-2)$ & $2(0-4)$ \\
\hline Range & $0-10$ & $0-3$ & $0-4$ & $0-14$ \\
\hline \multicolumn{5}{|l|}{10 to $<12$} \\
\hline$N$ transfused $/ N$ total, $\%$ transfused & $2 / 3(66.7 \%)$ & $2 / 12(16.7 \%)$ & $47 / 100(47.0 \%)$ & $251 / 370(67.8 \%)$ \\
\hline Median (IQR) & $1(0-6)$ & $0(0-0)$ & $0(0-2)$ & $2(0-3)$ \\
\hline Range & $0-6$ & $0-2$ & $0-8$ & $0-20$ \\
\hline \multicolumn{5}{|l|}{$12+$} \\
\hline$N$ transfused $/ N$ total, $\%$ transfused & $2 / 7(28.6 \%)$ & $4 / 52(7.7 \%)$ & $90 / 505(17.8 \%)$ & $966 / 2615(36.9 \%)$ \\
\hline Median (IQR) & $0(0-1)$ & $0(0-0)$ & $0(0-0)$ & $0(0-2)$ \\
\hline Range & $0-2$ & $0-2$ & $0-5$ & $0-33$ \\
\hline \multicolumn{5}{|l|}{$\mathrm{AB}$} \\
\hline \multicolumn{5}{|l|}{$<10$} \\
\hline$N$ transfused $/ N$ total, $\%$ transfused & $118 / 359(32.9 \%)$ & $186 / 377(49.3 \%)$ & $238 / 361(65.9 \%)$ & $149 / 179(83.2 \%)$ \\
\hline Median (IQR) & $0(0-1)$ & $0(0-2)$ & $1(0-2)$ & $2(1-5)$ \\
\hline Range & $0-8$ & $0-17$ & $0-8$ & $0-20$ \\
\hline \multicolumn{5}{|l|}{10 to $<12$} \\
\hline$N$ transfused $/ N$ total, $\%$ transfused & $154 / 1,148(13.4 \%)$ & $264 / 1,126(23.4 \%)$ & $505 / 1,079(46.8 \%)$ & $355 / 463(76.7 \%)$ \\
\hline Median (IQR) & $0(0-0)$ & $0(0-0)$ & $0(0-2)$ & $2(1-4)$ \\
\hline Range & $0-9$ & $0-20$ & $0-12$ & $0-20$ \\
\hline \multicolumn{5}{|l|}{$12+$} \\
\hline$N$ transfused $/ N$ total, $\%$ transfused & $133 / 4,419(3.0 \%)$ & $267 / 4,245(6.3 \%)$ & $655 / 3,581(18.3 \%)$ & $845 / 1,713(49.3 \%)$ \\
\hline Median (IQR) & $0(0-0)$ & $0(0-0)$ & $0(0-0)$ & $0(0-2)$ \\
\hline Range & $0-11$ & $0-13$ & $0-13$ & $0-44$ \\
\hline
\end{tabular}

$\mathrm{AB}$, arterial bypass; $\mathrm{IQR}$, interquartile range. 


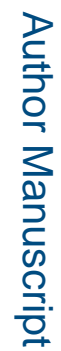

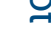

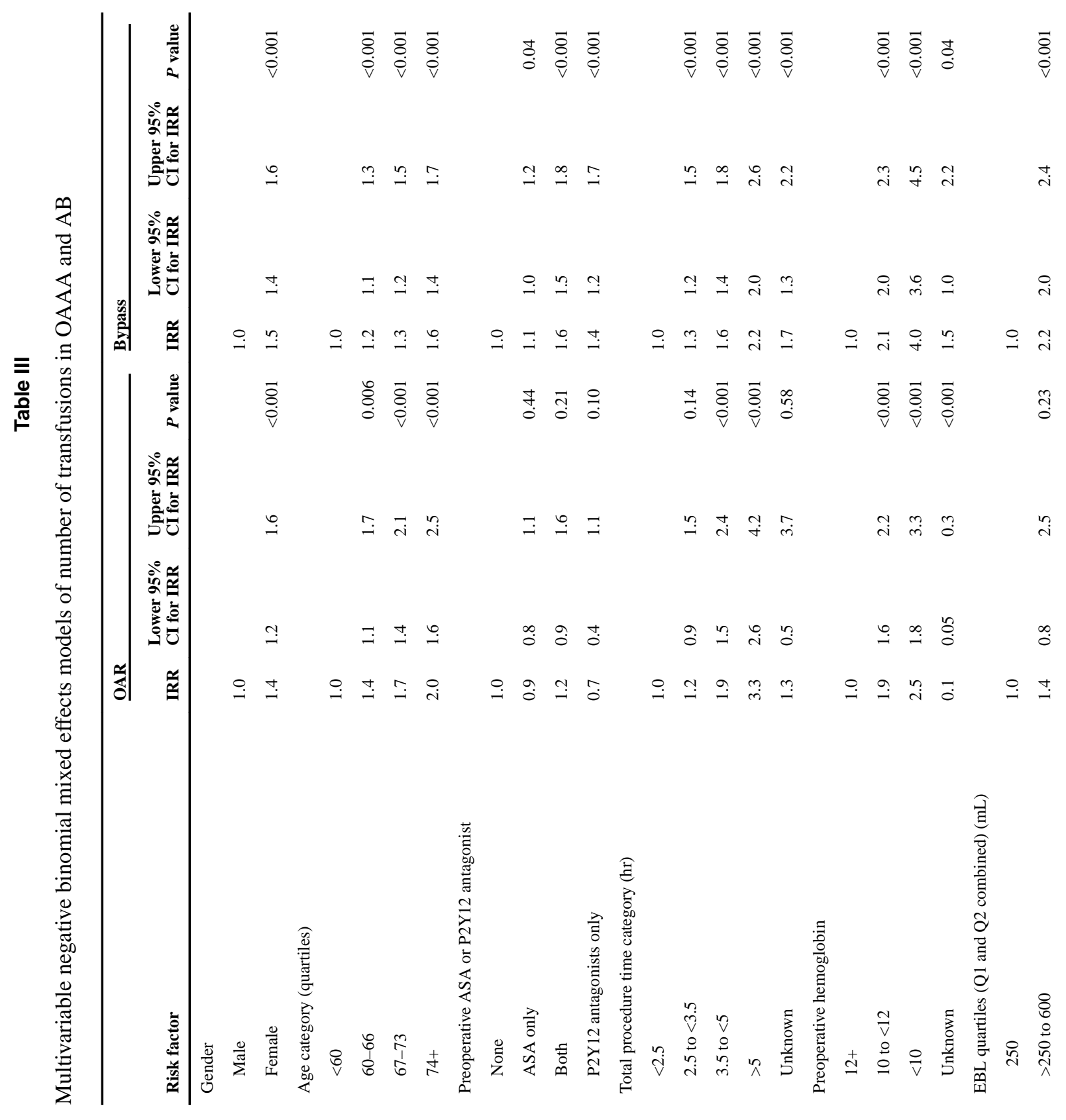




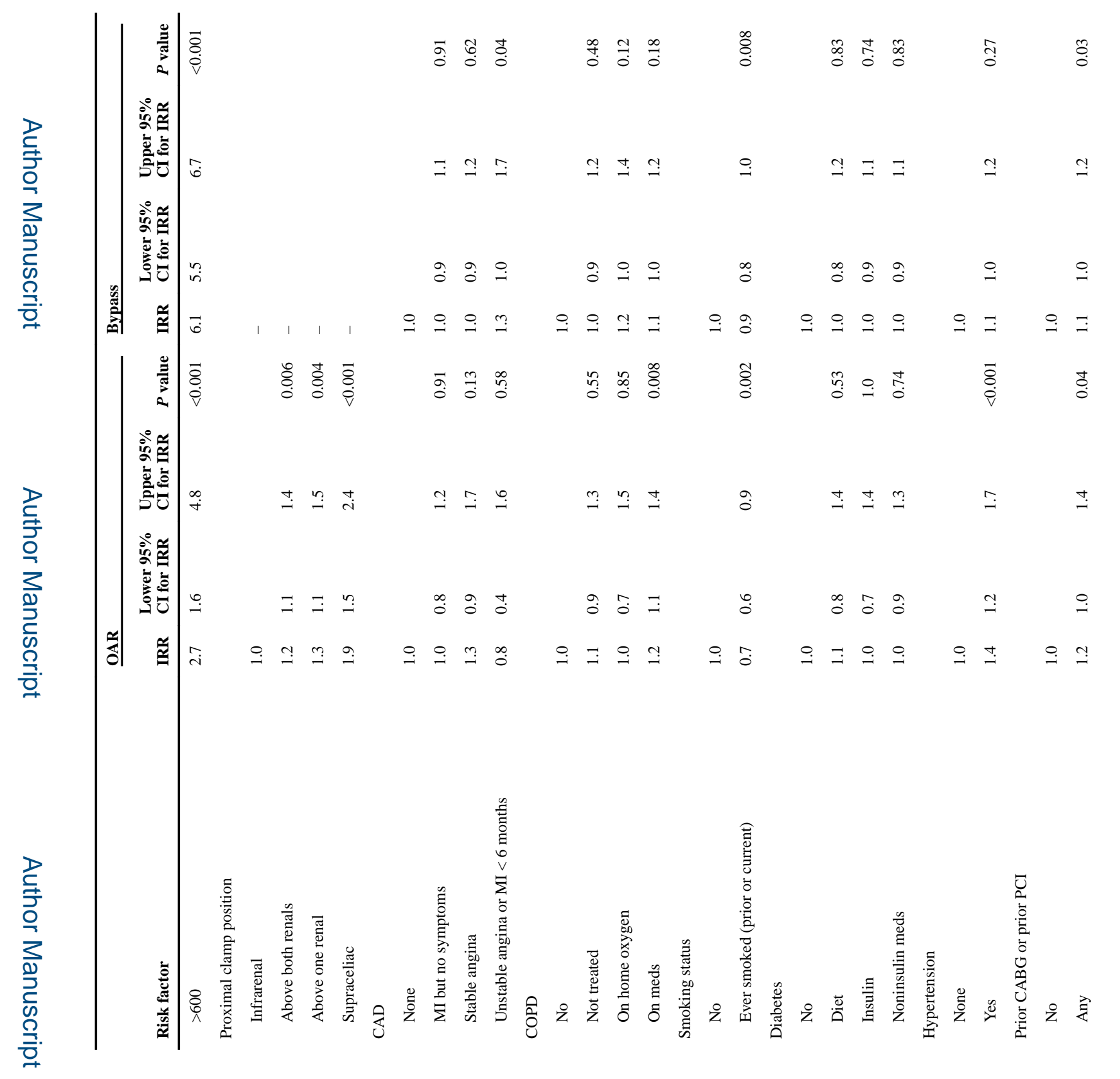

로을

Ann Vasc Surg. Author manuscript; available in PMC 2018 August 29. 


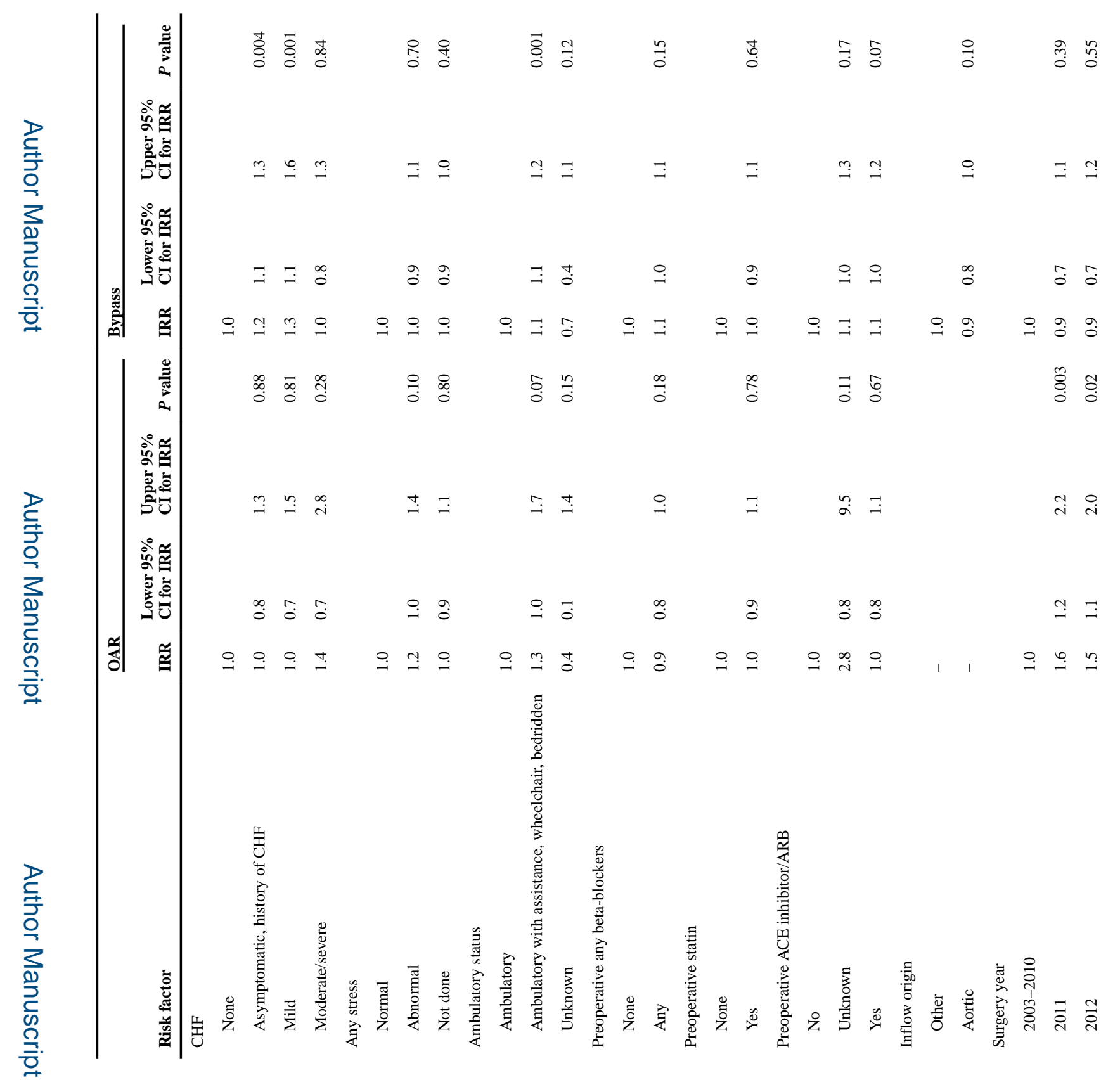

로을

Ann Vasc Surg. Author manuscript; available in PMC 2018 August 29. 


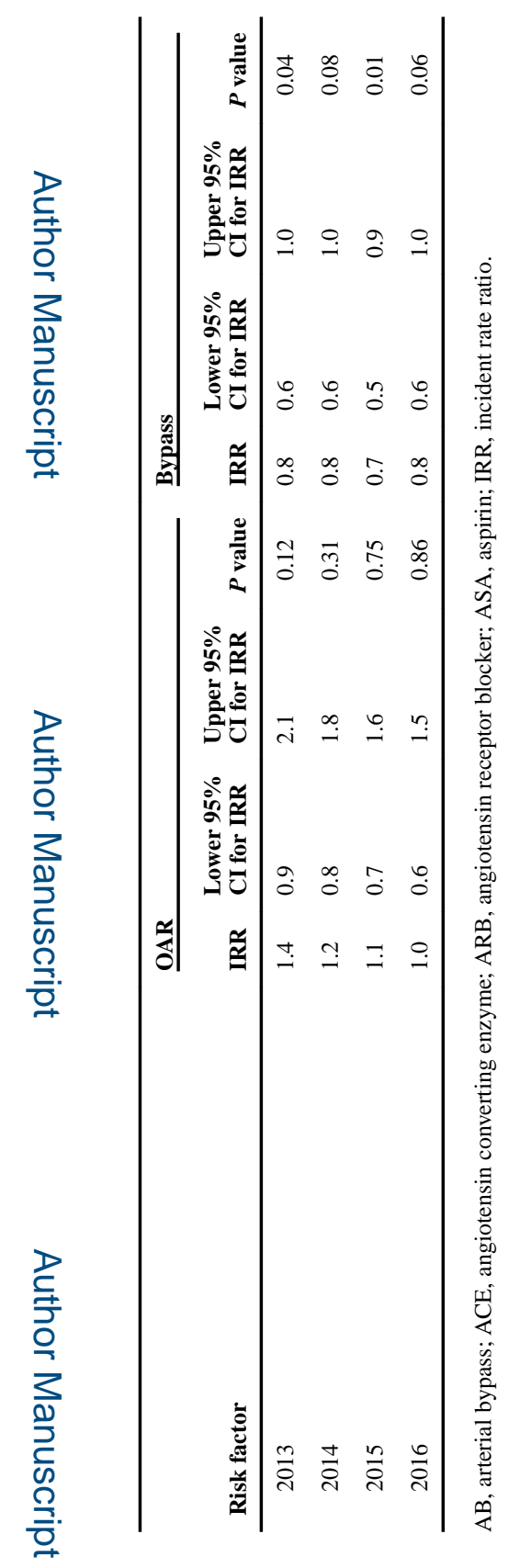

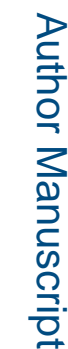




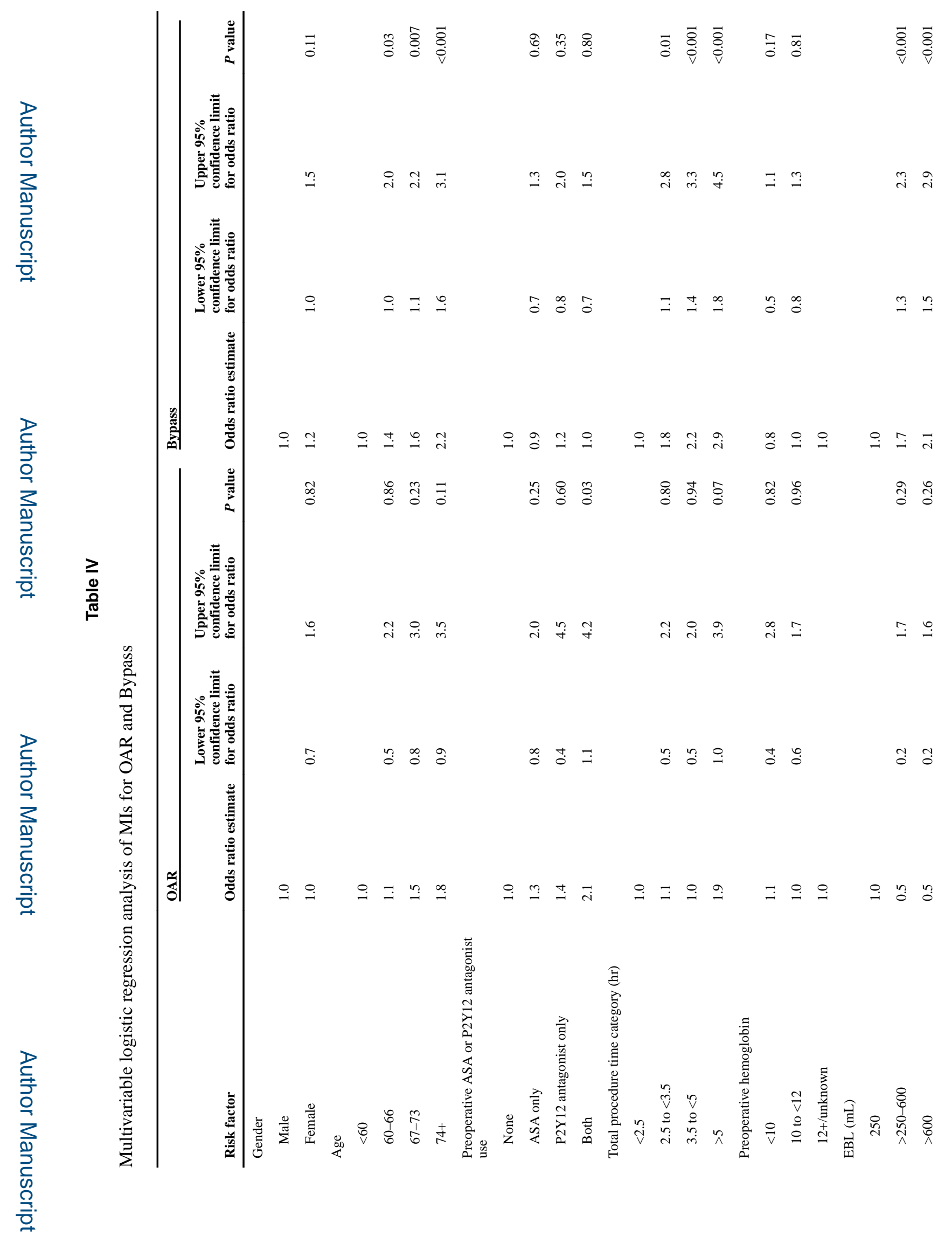

Ann Vasc Surg. Author manuscript; available in PMC 2018 August 29. 


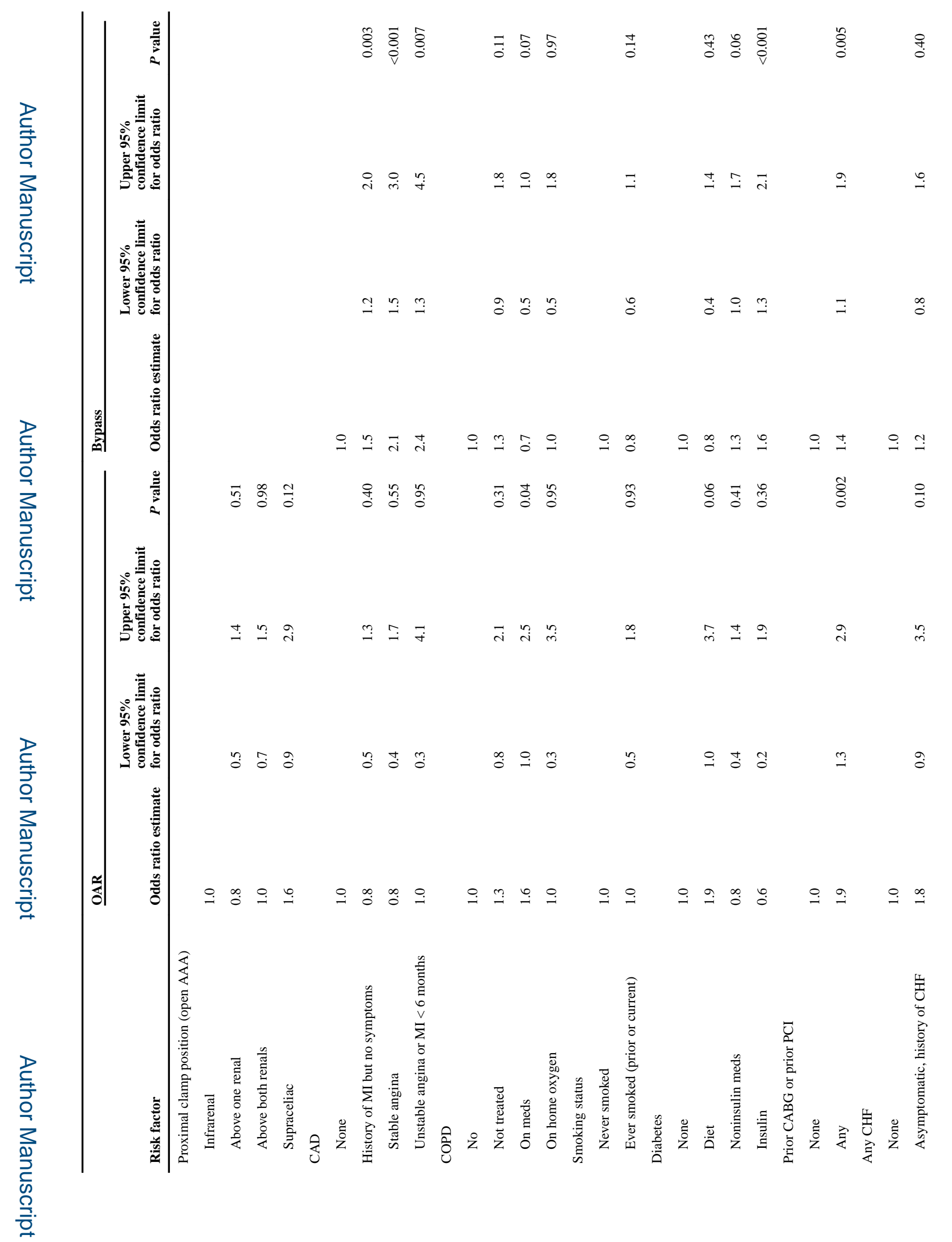

Ann Vasc Surg. Author manuscript; available in PMC 2018 August 29. 


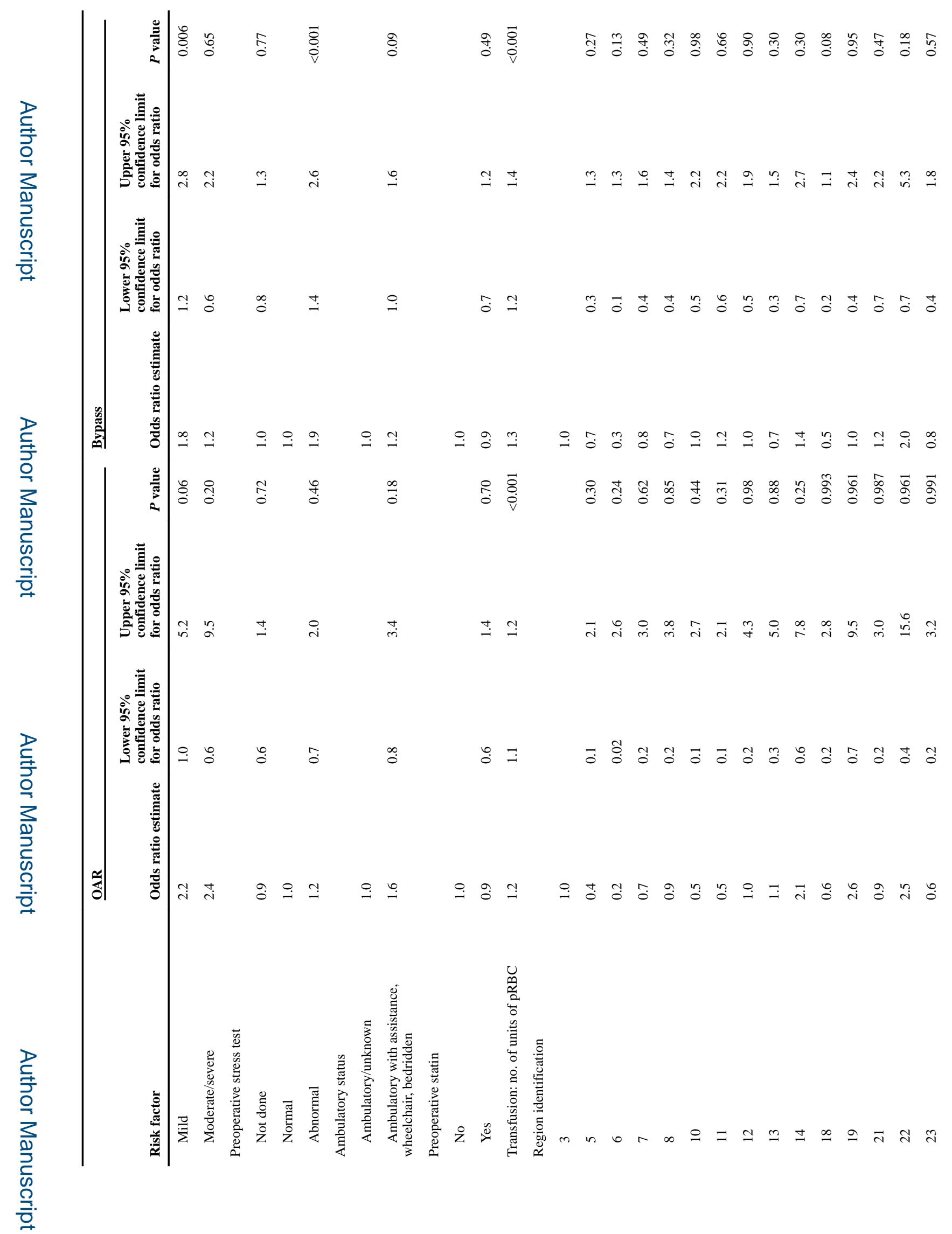

Ann Vasc Surg. Author manuscript; available in PMC 2018 August 29. 


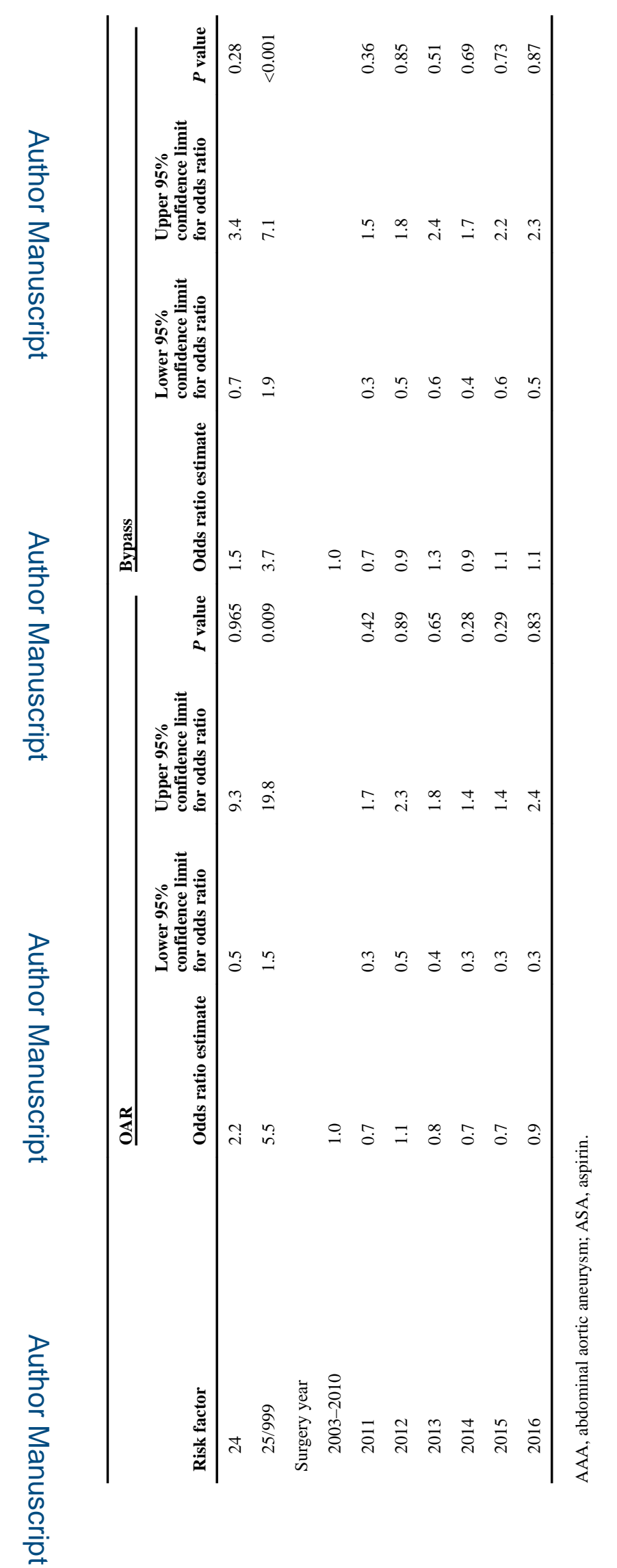

Ann Vasc Surg. Author manuscript; available in PMC 2018 August 29. 


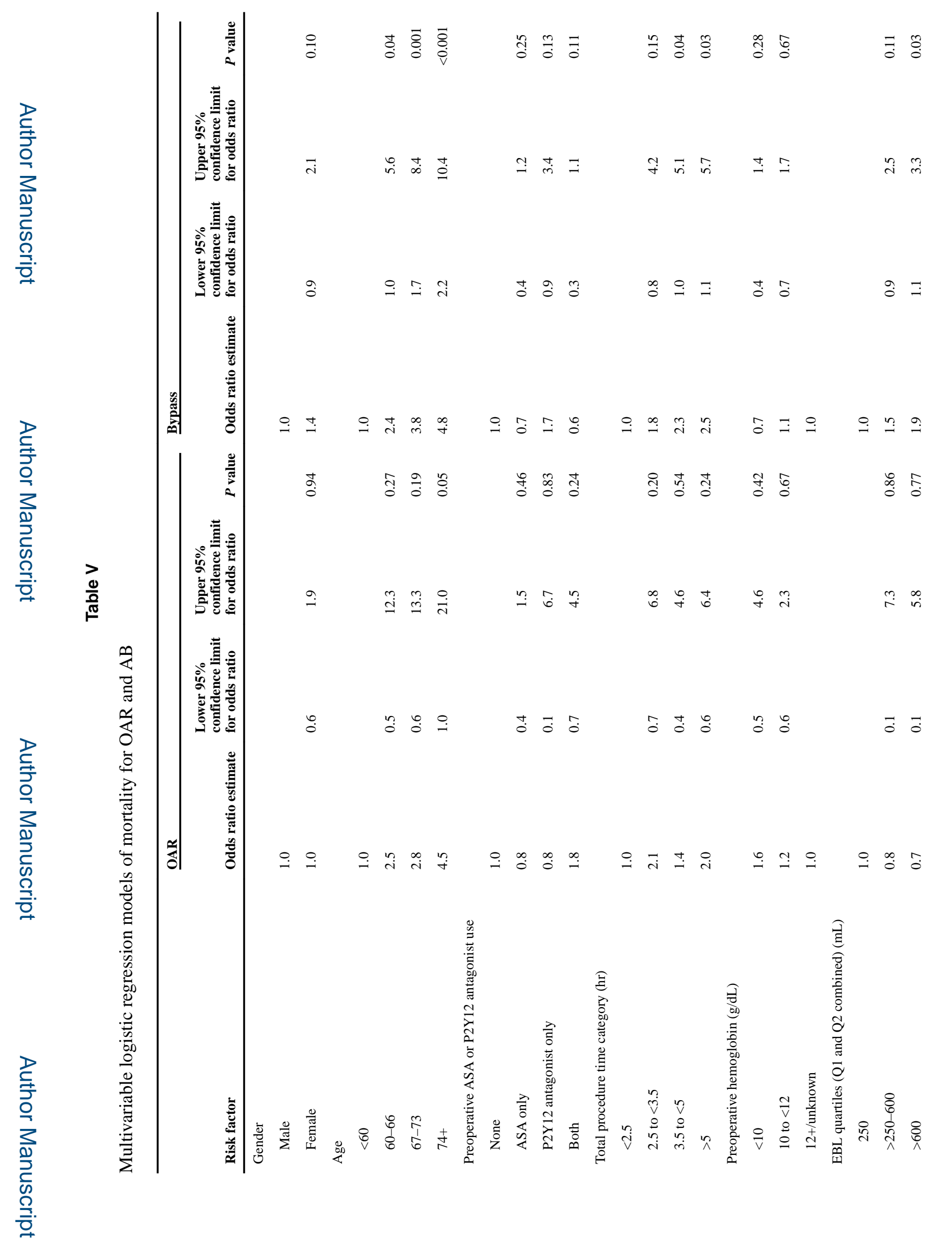

Ann Vasc Surg. Author manuscript; available in PMC 2018 August 29. 


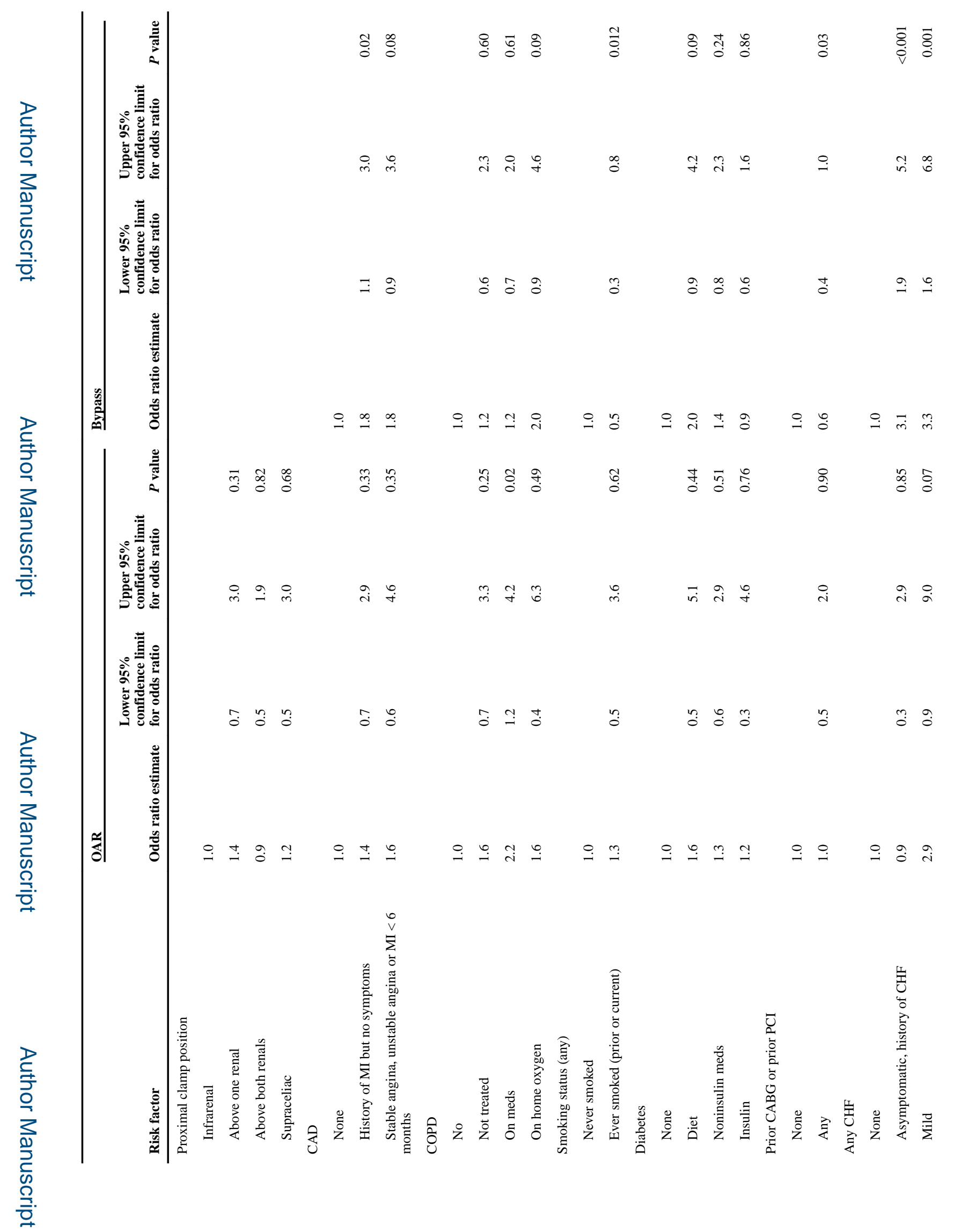

Ann Vasc Surg. Author manuscript; available in PMC 2018 August 29. 


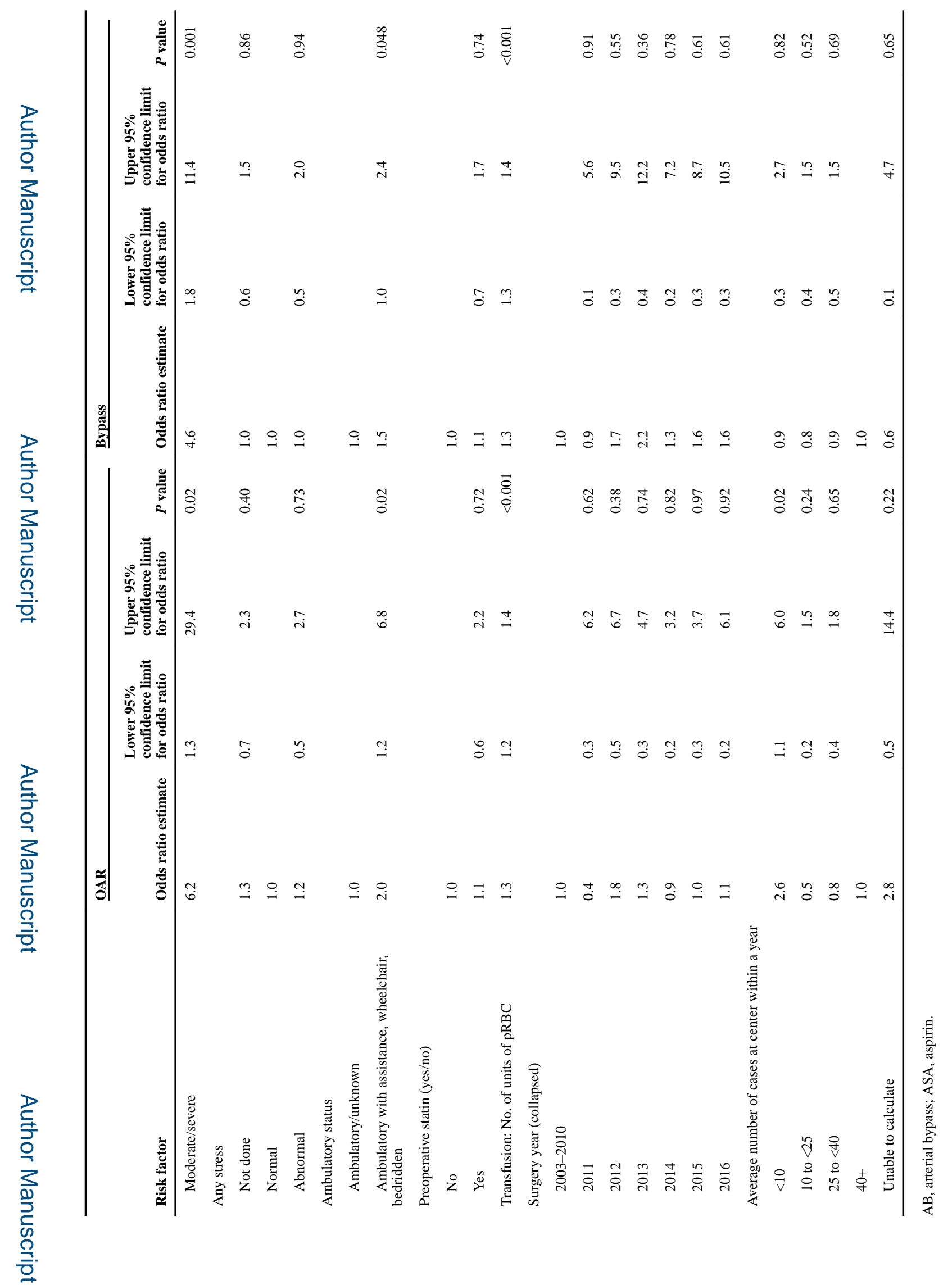

Ann Vasc Surg. Author manuscript; available in PMC 2018 August 29. 